\title{
SCIENTIFIC REPORTS

\section{OPEN Short Stature is Associated with Increased Risk of Dyslipidemia in Korean Adolescents and Adults}

Received: 19 May 2019

Accepted: 12 September 2019

Published online: 01 October 2019
Na-Kyung $\mathrm{Oh}^{1}$, Yun-Mi Song ${ }^{2}$, Shin-Hye Kim ${ }^{1}$ \& Mi Jung Park ${ }^{1}{ }^{1}$

Adults with short stature have been previously reported to have increased risk of cardiovascular events and hyper-LDL-cholesterolemia. We aimed to assess the association between height and lipid profiles among Korean adolescents and adults. We analyzed data from the Korea National Health and Nutrition Examination Survey from 2007 to 2015, from 37,889 individuals (aged 12-59 years). In adolescents, total cholesterol (TC) and low density lipoprotein-cholesterol (LDL-C) levels had profound associations with height in both boys and girls, while high density lipoprotein-cholesterol (HDL-C) levels had an inverse association with height only in boys. Height was inversely associated with TC, triglycerides (TG), and LDL-C concentrations in men and women and positively correlated with HDL-C concentration in women. In boys, the odds ratios (ORs) for hypercholesterolemia, hypertriglyceridemia, hyper-LDLcholesterolemia were higher for shorter subjects (ORs $=2.38 \sim 7.01$ ), while only the OR of hyper-LDLcholesterolemia was significantly higher in girls with short stature $(O R=3.12)$. In adults, the ORs for hypercholesterolemia, hypo-HDL-cholesterolemia, and hyper-LDL-cholesterolemia were significantly higher in short subjects than in tall subjects after controlling for covariates (ORs=1.50 2.61). Also, short men showed significantly higher ORs for hypertriglyceridemia $(O R=1.85)$ than tall men. Short stature was significantly associated with adverse lipid profiles in both adolescents and adults.

Height is recognized as an important indicator that reflects genetic and environmental factors, including nutrition, hormonal regulation, pubertal development, and chronic disease during the fetal-to-adolescent period. Following the first report in 1951 of the increased risk of coronary heart disease (CHD) with short stature in adults, this inverse association between adult height and cardiovascular disease (CVD) risk has been supported by the results of several prospective large-scale studies and meta-analyses. A meta-analysis of the relationship between height and CHD revealed that short adults had $\sim 1.5$ times higher risk for CHD morbidity and mortality than adults with tall stature ${ }^{1}$. Another meta-analysis with 1 million subjects reported that the risk of fatal or non-fatal coronary artery disease (CAD) decreases by $8 \%$ per every $6.5 \mathrm{~cm}$ increase in height ${ }^{2}$. Similarly, previous studies from Korea have reported a negative association between height and all-cause mortality ${ }^{3,4}$.

Dyslipidemia is one of the major established risk factors for CVD; treatment of dyslipidemia ameliorates the risk of CVD, and dyslipidemia has been reported to be inversely associated with adult height ${ }^{5-7}$. Lipid levels in childhood often track to adulthood. Although CVD usually develops in later life, it is well known that the accumulation of intimal fatty streaks, which are early atherosclerotic lesions, develops from childhood in association with dyslipidemia. Furthermore, dyslipidemia often accompanies other CVD risk factors including insulin resistance and hypertension, which exacerbate atherosclerosis. The identification of risk factors for dyslipidemia in children and adolescents is therefore essential for its early detection and management and the consequent prevention of CVD in later life ${ }^{8}$. In Korea, the overall prevalence of dyslipidemia in adolescents aged 10-18 years is $21.7 \sim 25.2 \%$; prevalence is reported to be two times higher $(53.1 \sim 56.1 \%)$ in obese adolescents 9 . However, few studies have been conducted on the relationship between height and blood lipid concentrations in children and adolescents $^{10-15}$. Specifically, there have been no studies on the association of dyslipidemia and height in Korean adolescents and adults. In the present study, we therefore aimed to assess the association between height and serum lipid profile in Korean adolescents and adults using data from the Korean National Health and Nutrition Examination Survey (KNHANES).

${ }^{1}$ Department of Pediatrics, Inje University Sanggye Paik Hospital, Seoul, Korea. ${ }^{2}$ Department of Family Medicine, Samsung Medical Center, Sungkyunkwan University School of Medicine, Seoul, Korea. Shin-Hye Kim and Mi Jung Park jointly supervised this work. Correspondence and requests for materials should be addressed to S.-H.K. (email: s2635@paik.ac.kr)or M.J.P. (email:pmj@paik.ac.kr) 


\section{Results}

General characteristics and lipid profiles of the study population. The mean age of the adolescents was 15.1 years, and the mean age of adult men and women were 38.9 and 39.3 years, respectively (Supplementary Table S1). Tables 1 and 2 shows the general characteristics of the study population according to the height percentile. No significant differences in age, fasting glucose, alcohol consumption, physical activity, and household income were found in adolescents by height percentile $(\mathrm{P}>0.05)$. Significantly higher body mass index $(\mathrm{BMI})(\mathrm{P}<0.001)$ in boys with higher height percentile was noted, while such association was not noted in girls. Also, significant elevation of systolic and diastolic blood pressures was found in boys $(\mathrm{P}<0.001)$, while only a modest but significant elevation of diastolic pressure was found in girls $(\mathrm{P}=0.002)$. No significant differences in age, $\mathrm{BMI}$, blood pressures were found according to the height percentile in men $(\mathrm{P}>0.05)$, while a modest but significant decreases in age, $\mathrm{BMI}$, and systolic blood pressure according to the elevation of height percentile were noted in women $(\mathrm{P}<0.05)$. Adults with higher height percentile showed significantly higher proportions of alcohol consumption, active physical activity, and higher household income than those with lower height percentile in both men and women $(\mathrm{P}<0.01)$. The prevalence of postmenopausal women was not significantly different by height percentile $(\mathrm{P}=0.114)$.

Relationship between lipid profile and height. Figure 1 shows the relationship between lipid profile and height percentile. In adolescents, total cholesterol (TC) and low density lipoprotein-cholesterol (LDL-C) levels showed inverse associations with height in boys and girls (P-for-trend $<0.05)$, while high density lipoprotein-cholesterol (HDL-C) levels had an inverse association with height only in boys (P-for-trend $<0.001$ ). TC, triglycerides (TG), and LDL-C levels were inversely associated with height in both men and women. HDL-C levels did not significantly associate with height in men, while they positively associated in women (P-for-trend $<0.001$ ). The prevalence of dyslipidemia according to height is shown in Fig. 2 and Supplementary Table S2. In adolescents, the prevalence of hypercholesterolemia and hyper-LDL-cholesterolemia was significantly higher in shorter subjects ( $\mathrm{P}$-for-trend $<0.05$ ), while that of hypo-HDL-cholesterolemia was significantly lower in shorter subjects (P-for-trend $<0.001$ ). No significant difference was observed in the prevalence of hypertriglyceridemia and dyslipidemia according to the height percentiles among adolescents. In adults, the prevalence of hypercholesterolemia, hyper-LDL-cholesterolemia, hypo-HDL-cholesterolemia, hypertriglyceridemia, and dyslipidemia was significantly higher in shorter subjects (P-for-trend $<0.01$ ).

ORs for dyslipidemia according to the height percentile. The odds ratios (ORs) and 95\% confidence intervals for dyslipidemia according to the height percentile are presented in Tables 3 and 4 . In boys, the ORs for hypercholesterolemia, hypertriglyceridemia, and hyper-LDL-cholesterolemia were significantly increased in shorter subjects than in taller subjects $(\mathrm{ORs}=2.38 \sim 7.01$, P-for-trend $<0.05)$, while the OR for hypo-HDL-cholesterolemia and dyslipidemia did not show any significant difference according to the height percentile (Table 3). In girls, only the OR for hyper-LDL-cholesterolemia was significantly increased in shorter subjects than in taller subjects $(\mathrm{OR}=3.12$, P-for-trend $=0.026)$. In both men and women, the ORs for hypercholesterolemia, hyper-LDL-cholesterolemia, and dyslipidemia were significantly increased in shorter subjects $(\mathrm{ORs}=1.50 \sim 2.61, \mathrm{P}<0.01)$ than in taller subjects (height $\geq 90$ percentile). Of note, a linear trend but an inverted $\mathrm{J}$-shaped association was observed in the relationship between height and hypo-HDL-cholesterolemia in women. While the OR (95\% confidence intervals) for hypo-HDL-cholesterolemia in women with heights between 10 and $29^{\text {th }}$ percentile was $1.54(1.02-2.33)$, the OR in women with heights less than $10^{\text {th }}$ percentile was $1.33(0.86-2.04)$. In men, the $\mathrm{OR}$ for hypertriglyceridemia $(\mathrm{OR}=1.85)$ was significantly increased in shorter subjects than in taller subjects in men, while such an increase in OR was not statistically significant in women (Table 4).

\section{Discussion}

The present study found that short stature has a significant inversely association with dyslipidemia in both Korean adolescents and adults. In adolescents, this inverse relationship between height and dyslipidemia showed sex-related differences. The risk of hypercholesterolemia, hypertriglyceridemia, and hyper-LDL-cholesterolemia was linked with height in boys, while only hyper-LDL-cholesterolemia was significantly related to height in girls. In adults, all four types of dyslipidemia were confirmed to be negatively affected by short stature in both men and women.

Since a small cross-sectional study from the 1980s reported a negative correlation between height and TC in boys ${ }^{10}$, a few prospective studies have analyzed the association between height gain and LDL-C levels in adolescents. The Bogalusa Heart Study reported that changes in height for five years in boys were inversely correlated with TC, LDL-C, and HDL-C levels ${ }^{12}$ (9). This negative correlation between the LDL-C concentration and growth rate in both boys and girls was also supported by the findings of large-scale prospective study conducted in Japan ${ }^{14}$. Finally, a recent study of 6,300 adolescents conducted by the West Virginia Coronary Artery Risk Detection in Appalachian Communities (CARDIAC) project reported that the risk of hyper-LDL-cholesterolemia increases significantly in the first (shortest) quartile stature compared with that in the fourth (tallest) quartile stature $(\mathrm{OR}=1.3 \sim 3)^{15}$. Consistent with previous studies, the present study also found that shorter adolescents had higher TC and LDL-C levels, with significantly increased OR for hyper-LDL-cholesterolemia $(\mathrm{OR}=3.12 \sim 4.35)$. Unlike those on LDL-C, studies on the association of TG with height are rare. A previous cross-sectional study in children and adolescents aged 13 to 18 years from the UK demonstrated no significant association between height and TG concentration ${ }^{10}$. Similarly, a longitudinal study among boys in the USA found no association between changes in TG levels and rapid height increase ${ }^{12}$. In contrast to this previous study, the present study found statistically higher OR for hypertriglyceridemia in shorter boys, and this association was not observed in girls. It is also important to note that obesity indices were significantly higher in boys with taller heights than in boys with shorter heights in this study population. These results suggest that the adverse effect of short stature on CVD risk in adolescents might be comparable or even stronger than obesity indices, especially for boys. 


\begin{tabular}{|c|c|c|c|c|c|c|}
\hline & \multicolumn{5}{|l|}{ Height percentile } & \multirow[b]{2}{*}{ P-value } \\
\hline & $<$ 10th & 10-29th & 30-69th & 70-89th & $\geq 90$ th & \\
\hline \multicolumn{7}{|l|}{ Boys } \\
\hline No. & 267 & 557 & 1102 & 571 & 279 & \\
\hline Age (year) & $15.1(14.8-15.3)$ & $15.0(14.8-15.2)$ & $15.2(15.0-15.3)$ & $15.0(14.9-15.2)$ & $15.1(14.8-15.3)$ & 0.768 \\
\hline Height $(\mathrm{cm})$ & $158.4(157.2-159.5)$ & $163.9(163.2-164.5)$ & $169.5(169.1-169.9)$ & $174.6(174.1-175.1)$ & $180.3(179.6-181.0)$ & $<0.001$ \\
\hline $\mathrm{WC}(\mathrm{cm})$ & $69.1(67.6-70.5)$ & $71.1(70.1-72.2)$ & $73.1(72.3-73.9)$ & $76.2(75.2-77.3)$ & $77.4(75.9-78.9)$ & $<0.001$ \\
\hline $\operatorname{BMI}\left(\mathrm{kg} / \mathrm{m}^{2}\right)$ & $20.4(19.9-21.0)$ & $21.0(20.6-21.4)$ & $21.4(21.1-21.7)$ & $22.1(21.7-22.5)$ & $22.1(21.6-22.7)$ & $<0.001$ \\
\hline Systolic BP (mmHg) & $107.9(106.0-109.8)$ & $109.6(108.6-110.6)$ & $110.4(109.6-111.2)$ & $112.5(111.5-113.5)$ & $111.2(109.8-112.6)$ & $<0.001$ \\
\hline Diastolic BP (mmHg) & $66.2(64.8-67.6)$ & $67.8(67.0-68.7)$ & $68.5(67.8-69.2)$ & $69.6(68.8-70.4)$ & $69.2(68.1-70.4)$ & $<0.001$ \\
\hline Fasting glucose (mg/dL) & $90.1(89.0-91.2)$ & $89.5(88.8-90.1)$ & $89.2(88.8-89.7)$ & $90.2(89.5-90.9)$ & $89.7(88.7-90.7)$ & 0.184 \\
\hline Alcohol consumption & & & & & & 0.376 \\
\hline No & $226(79.0 \%)$ & $491(86.4 \%)$ & $949(83.2 \%)$ & $497(83.5 \%)$ & $233(82.2 \%)$ & \\
\hline Occasionally & $34(19.3 \%)$ & $56(12.7 \%)$ & $128(14.8 \%)$ & $64(15.2 \%)$ & $36(14.8 \%)$ & \\
\hline Excessively & $3(1.7 \%)$ & $5(0.9 \%)$ & $17(2.0 \%)$ & $6(1.3 \%)$ & $6(3.0 \%)$ & \\
\hline Physical activity & & & & & & 0.787 \\
\hline No & $160(59.0 \%)$ & $333(58.9 \%)$ & $634(57.1 \%)$ & $325(57.4 \%)$ & $165(61.7 \%)$ & \\
\hline Yes & $102(41.0 \%)$ & $217(41.1 \%)$ & $457(42.9 \%)$ & $241(42.6 \%)$ & $109(38.3 \%)$ & \\
\hline Household income & & & & & & 0.399 \\
\hline Quartile 1 & $37(14.4 \%)$ & $65(13.7 \%)$ & $130(12.9 \%)$ & $59(11.8 \%)$ & $28(12.7 \%)$ & \\
\hline Quartile 2 & $73(32.2 \%)$ & $127(26.5 \%)$ & $241(25.9 \%)$ & $139(26.4 \%)$ & $66(24.7 \%)$ & \\
\hline Quartile 3 & $77(32.2 \%)$ & $185(26.0 \%)$ & $341(25.9 \%)$ & $184(26.4 \%)$ & $85(24.7 \%)$ & \\
\hline Quartile 4 & $80(27.3 \%)$ & $170(28.0 \%)$ & $371(32.9 \%)$ & $186(30.0 \%)$ & $96(31.6 \%)$ & \\
\hline \multicolumn{7}{|l|}{ Girls } \\
\hline No. & 236 & 487 & 976 & 484 & 248 & \\
\hline Age (year) & $15.2(14.9-15.5)$ & $15.0(14.8-15.2)$ & $15.05(14.9-15.2)$ & $15.1(14.9-15.3)$ & $15.3(15.0-15.6)$ & 0.574 \\
\hline Height $(\mathrm{cm})$ & $150.0(149.4-150.7)$ & $155.2(155.0-155.5)$ & $\begin{array}{l}159.9(15938- \\
160.1)\end{array}$ & $164.5(164.3-164.7)$ & $169.2(168.9-169.5)$ & $<0.001$ \\
\hline $\mathrm{WC}(\mathrm{cm})$ & $65.7(64.6-66.9)$ & $67.6(66.7-68.5)$ & $68.7(69.6-71.6)$ & $70.6(69.6-71.6)$ & $71.5(70.5-72.5)$ & $<0.001$ \\
\hline $\operatorname{BMI}\left(\mathrm{kg} / \mathrm{m}^{2}\right)$ & $20.5(20.0-21.0)$ & $20.9(20.6-21.4)$ & $20.8(20.6-21.1)$ & $21.0(20.6-21.4)$ & $21.1(20.7-21.6)$ & 0.390 \\
\hline Systolic BP (mmHg) & $103.1(101.6-104.8)$ & $103.8(102.9-104.7)$ & $104.3(103.6-105.1)$ & $105.3(104.3-106.3)$ & $105.1(103.9-106.3)$ & 0.093 \\
\hline Diastolic BP (mmHg) & $65.8(64.3-67.3)$ & $65.8(65.0-66.7)$ & $66.3(65.6-66.9)$ & 67.6 (66.8-68.5) & $67.9(66.8-69.1)$ & 0.002 \\
\hline Fasting glucose (mg/dL) & $89.4(86.8-92.0)$ & $88.2(87.4-88.9)$ & $88.2(87.7-88.7)$ & $88.6(87.9-89.3)$ & 89.5 (88.6-90.4) & 0.150 \\
\hline Alcohol consumption & & & & & & 0.481 \\
\hline No & $212(88.9 \%)$ & $441(90.3 \%)$ & $887(88.0 \%)$ & $439(88.9 \%)$ & $219(87.4 \%)$ & \\
\hline Occasionally & $17(9.1 \%)$ & $33(7.8 \%)$ & $79(11.0 \%)$ & $36(9.4 \%)$ & $24(12.4 \%)$ & \\
\hline Excessively & $4(2.0 \%)$ & $5(1.9 \%)$ & $7(1.0 \%)$ & $6(1.7 \%)$ & $1(0.2 \%)$ & \\
\hline Physical activity & & & & & & 0.342 \\
\hline No & $162(70.2 \%)$ & $320(64.1 \%)$ & $664(67.2 \%)$ & $329(69.1 \%)$ & $162(62.1 \%)$ & \\
\hline Yes & $70(29.8 \%)$ & $158(35.9 \%)$ & $308(32.8 \%)$ & $148(30.9 \%)$ & $82(37.9 \%)$ & \\
\hline Household income & & & & & & 0.647 \\
\hline Quartile 1 & $33(15.9 \%)$ & $66(15.4 \%)$ & $119(14.2 \%)$ & $55(13.4 \%)$ & $25(11.3 \%)$ & \\
\hline Quartile 2 & $71(32.3 \%)$ & $136(29.2 \%)$ & $233(24.6 \%)$ & $109(25.4 \%)$ & $64(28.8 \%)$ & \\
\hline Quartile 3 & $76(29.1 \%)$ & $144(28.7 \%)$ & $305(32.2 \%)$ & $161(32.3 \%)$ & $79(31.3 \%)$ & \\
\hline Quartile 4 & $53(22.7 \%)$ & $135(26.7 \%)$ & $309(29.0 \%)$ & $150(28.9 \%)$ & $76(28.6 \%)$ & \\
\hline
\end{tabular}

Table 1. General characteristics of the subjects according to the height percentile in 5,207 adolescents. The data were present as mean (95\% confidence interval) or number (\%). BMI, body mass index; BP, blood pressure; WC, waist circumference.

Unlike the negative correlation between height and LDL-C in both boys and girls, which is reported by most studies, reports on the relationship between height and HDL-C are inconsistent. In previous studies from the UK and USA, HDL-C levels were negatively associated with height increase in boys, but not in girls, aged 8 to 18 years $^{10,12}$. Another study from Japan reported a negative correlation between HDL-C levels and height in both sexes in the age of 10-14 years ${ }^{13}$. In the present study, height was negatively correlated with HDL-C levels, only in boys, but its association with hypo-HDL-cholesterolemia was not statistically significant after adjusting for relevant covariates. In contrast with adolescents, adults with shorter height percentile showed a significantly higher risk of hypo-HDL-cholesterolemia, which might be explained by the effects of aging on HDL metabolism. Increased insulin resistance and systemic inflammation, a decline of sex hormone, and impaired lecithin cholesterol acyltransferase activity due to cellular senescence ${ }^{16}$ may enforce the inverse relationship between height and HDL-cholesterol 


\begin{tabular}{|c|c|c|c|c|c|c|}
\hline & \multicolumn{5}{|l|}{ Height percentile } & \multirow[b]{2}{*}{ P-value } \\
\hline & $<10^{\text {th }}$ & 10-29th & 30-69th & 70-89th & $\geq 90$ th & \\
\hline \multicolumn{7}{|l|}{ Men } \\
\hline No. & 1375 & 2696 & 5463 & 2727 & 1383 & \\
\hline Age (yr) & \begin{tabular}{|l|l|}
$39.4(38.7-40.1)$ \\
\end{tabular} & $39.0(38.5-39.5)$ & $38.9(38.5-39.3)$ & $38.6(38.1-39.1)$ & $38.5(37.8-39.2)$ & 0.306 \\
\hline Height $(\mathrm{cm})$ & $161.6(161.4-161.8)$ & $167.2(167.2-167.3)$ & $171.9(171.9-172.0)$ & $176.8(176.7-176.9)$ & $182.1(181.9-182.3)$ & $<0.001$ \\
\hline Weight(kg) & $62.9(62.4-63.5)$ & $67.6(67.2-68.0)$ & $71.6(71.3-71.9)$ & $75.8(75.3-76.2)$ & $81.2(80.4-81.9)$ & $<0.001$ \\
\hline $\mathrm{WC}(\mathrm{cm})$ & $80.9(80.3-81.4)$ & $82.4(83.7-84.2)$ & $83.9(83.7-84.2)$ & $85.4(84.9-85.8)$ & $87.4(86.8-88.0)$ & $<0.001$ \\
\hline $\operatorname{BMI}\left(\mathrm{kg} / \mathrm{m}^{2}\right)$ & $24.0(23.8-24.2)$ & $24.1(24.0-24.3)$ & $24.2(24.1-24.3)$ & $24.3(24.1-24.4)$ & $24.5(24.3-24.7)$ & 0.169 \\
\hline Systolic BP (mmHg) & $118.2(117.3-119.1)$ & $118.2(117.5-118.8)$ & $117.6(117.2-118.1)$ & $117.7(117.1-118.3)$ & $117.6(116.7-118.4)$ & 0.480 \\
\hline Diastolic BP (mmHg) & \begin{tabular}{|l|l}
$78.6(77.9-79.3)$ \\
\end{tabular} & $79.4(78.9-79.8)$ & \begin{tabular}{|l|}
$79.3(78.9-79.6)$ \\
\end{tabular} & $79.4(78.9-79.8)$ & $79.5(78.9-80.1)$ & 0.339 \\
\hline Fasting glucose (mg/dL) & $96.7(95.4-98.9)$ & $96.3(95.4-97.1)$ & $96.9(96.3-97.6)$ & $96.6(95.7-97.4)$ & $98.3(96.9-99.8)$ & 0.159 \\
\hline Alcohol consumption & & & & & & 0.017 \\
\hline No & $364(36.5 \%)$ & $590(22.5 \%)$ & $1104(20.6 \%)$ & $558(21.1 \%)$ & $272(21.2 \%)$ & \\
\hline Occasionally & $701(52.4 \%)$ & $1398(54.1 \%)$ & $2955(56.4 \%)$ & $1465(55.0 \%)$ & $727(55.3 \%)$ & \\
\hline Excessively & $272(21.0 \%)$ & $622(23.4 \%)$ & $1248(23.0 \%)$ & $623(23.9 \%)$ & $335(23.4 \%)$ & \\
\hline Physical activity & & & & & & 0.001 \\
\hline No & $936(69.7 \%)$ & $1764(67.9 \%)$ & $3595(67.5 \%)$ & $1778(66.9 \%)$ & $844(61.1 \%)$ & \\
\hline Yes & $392(30.3 \%)$ & $819(32.1 \%)$ & $1662(32.5 \%)$ & $834(33.1 \%)$ & $473(38.9 \%)$ & \\
\hline Household income & & & & & & $<0.001$ \\
\hline Quartile 1 & $160(12.4 \%)$ & $251(9.3 \%)$ & $458(9.1 \%)$ & $149(6.5 \%)$ & $87(6.4 \%)$ & \\
\hline Quartile 2 & $395(29.7 \%)$ & $678(26.9 \%)$ & $1217(23.6 \%)$ & $584(22.6 \%)$ & $288(21.2 \%)$ & \\
\hline Quartile 3 & $424(31.0 \%)$ & $829(31.6 \%)$ & $1772(32.5 \%)$ & $910(34.8 \%)$ & $452(33.8 \%)$ & \\
\hline Quartile 4 & $376(26.9 \%)$ & $896(32.1 \%)$ & $1948(34.8 \%)$ & $1049(36.2 \%)$ & $544(38.7 \%)$ & \\
\hline \multicolumn{7}{|l|}{ Women } \\
\hline No. & 1932 & 3736 & 7616 & 3853 & 1901 & \\
\hline Age (yr) & $39.5(38.9-40.2)$ & $39.5(39.1-40.0)$ & $39.4(39.1-39.8)$ & $39.0(18.6-39.5)$ & $38.6(38.0-38.2)$ & 0.038 \\
\hline Height $(\mathrm{cm})$ & $149.6(149.5-149.8)$ & $154.4(154.3-154.5)$ & $158.9(158.8-159.0)$ & $163.5(163.4-163.6)$ & $168.4(168.2-168.6)$ & $<0.001$ \\
\hline $\mathrm{WC}(\mathrm{cm})$ & \begin{tabular}{|l|l}
$75.4(74.9-75.9)$ \\
\end{tabular} & $75.7(75.3-76.1)$ & $76.2(75.9-76.4)$ & $77.2(76.8-77.6)$ & $77.8(77.3-78.4)$ & $<0.001$ \\
\hline $\operatorname{BMI}\left(\mathrm{kg} / \mathrm{m}^{2}\right)$ & $23.5(23.3-23.7)$ & $23.1(22.9-23.3)$ & $22.8(22.7-22.9)$ & $22.7(22.6-22.8)$ & $22.4(22.2-22.6)$ & $<0.001$ \\
\hline Systolic BP (mmHg) & $111.3(110.4-112.1)$ & $110.2(109.7-110.8)$ & $110.2(109.7-110.8)$ & $109.7(1109.2-110.3)$ & $109.0(108.3-109.8)$ & 0.001 \\
\hline Diastolic BP (mmHg) & \begin{tabular}{|l|}
$72.5(71.9-73.1)$ \\
\end{tabular} & $72.4(71.9-72.8)$ & $72.7(72.4-73.0)$ & $72.8(72.4-73.2)$ & $72.8(72.3-73.3)$ & 0.465 \\
\hline Fasting glucose (mg/dL) & $92.7(91.8-93.6)$ & $93.1(92.5-93.9)$ & $92.9(92.4-93.4)$ & $92.6(91.9-93.1)$ & $92.6(91.9-93.4)$ & 0.687 \\
\hline Alcohol consumption & & & & & & $<0.001$ \\
\hline No & $1080(55.5 \%)$ & $1977(52.3 \%)$ & $3913(50.6 \%)$ & $1942(49.3 \%)$ & $979(49.6 \%)$ & \\
\hline Occasionally & $728(39.7 \%)$ & $1508(42.5 \%)$ & $3149(43.6 \%)$ & $1600(43.9 \%)$ & $770(43.1 \%)$ & \\
\hline Excessively & $87(4.7 \%)$ & $173(5.2 \%)$ & $422(5.9 \%)$ & $228(6.8 \%)$ & $116(7.3 \%)$ & \\
\hline Physical activity & & & & & & $<0.001$ \\
\hline No & $1442(76.4 \%)$ & $2697(73.8 \%)$ & $5464(72.9 \%)$ & $2652(69.8 \%)$ & $1301(70.5 \%)$ & \\
\hline Yes & $443(23.6 \%)$ & $942(26.2 \%)$ & $1942(27.1 \%)$ & $1095(30.2 \%)$ & $539(29.5 \%)$ & \\
\hline Household income & & & & & & $<0.001$ \\
\hline Quartile 1 & $253(13.2 \%)$ & $354(9.3 \%)$ & $595(8.2 \%)$ & $312(8.7 \%)$ & $136(7.3 \%)$ & \\
\hline Quartile 2 & $571(30.5 \%)$ & $988(37.2 \%)$ & $1884(26.4 \%)$ & $872(23.1 \%)$ & $415(23.2 \%)$ & \\
\hline Quartile 3 & $592(30.5 \%)$ & $1216(27.2 \%)$ & $2406(26.4 \%)$ & $1226(23.1 \%)$ & $583(23.2 \%)$ & \\
\hline Quartile 4 & $493(24.8 \%)$ & $1145(30.4 \%)$ & $2638(34.0 \%)$ & $1392(35.1 \%)$ & $738(38.0 \%)$ & \\
\hline Menopause & & & & & & 0.114 \\
\hline No & $1426(77.6 \%)$ & $2796(78.8 \%)$ & $5770(79.5 \%)$ & $2943(79.9 \%)$ & $1496(81.3 \%)$ & \\
\hline Yes & $506(22.4 \%)$ & $940(21.2 \%)$ & $1846(20.5 \%)$ & $910(20.1 \%)$ & $405(18.7 \%)$ & \\
\hline
\end{tabular}

Table 2. General characteristics of the subjects according to the height percentile in 32,682 adults. The data were present as mean (95\% confidence interval) or number (\%). All continuous variables were adjusted for age in women. BMI, body mass index; BP, blood pressure; WC, waist circumference.

in adults. The results of studies on the relationship between height and dyslipidemia/lipid concentration in adults have been inconsistent. Two prospective cohort studies from Europe reported an association between greater leg length and favorable levels of TC, LDL-C, and HDL-C at 53 years in UK adults ${ }^{6}$ and between taller stature and lower non-fasting TC and non-HDL-C levels in middle-aged men ${ }^{5}$. These two studies did not include TG concentration. In a study of individuals aged 50 years and older in China, height was negatively correlated with both LDL-C and HDL-C levels and positively correlated with TG concentration ${ }^{7}$. In a hospital-based study of 3,016 patients aged 30-59 years in Japan, no significant correlation was found between height and individual lipid profiles, but the OR 
Boys

Girls

Men
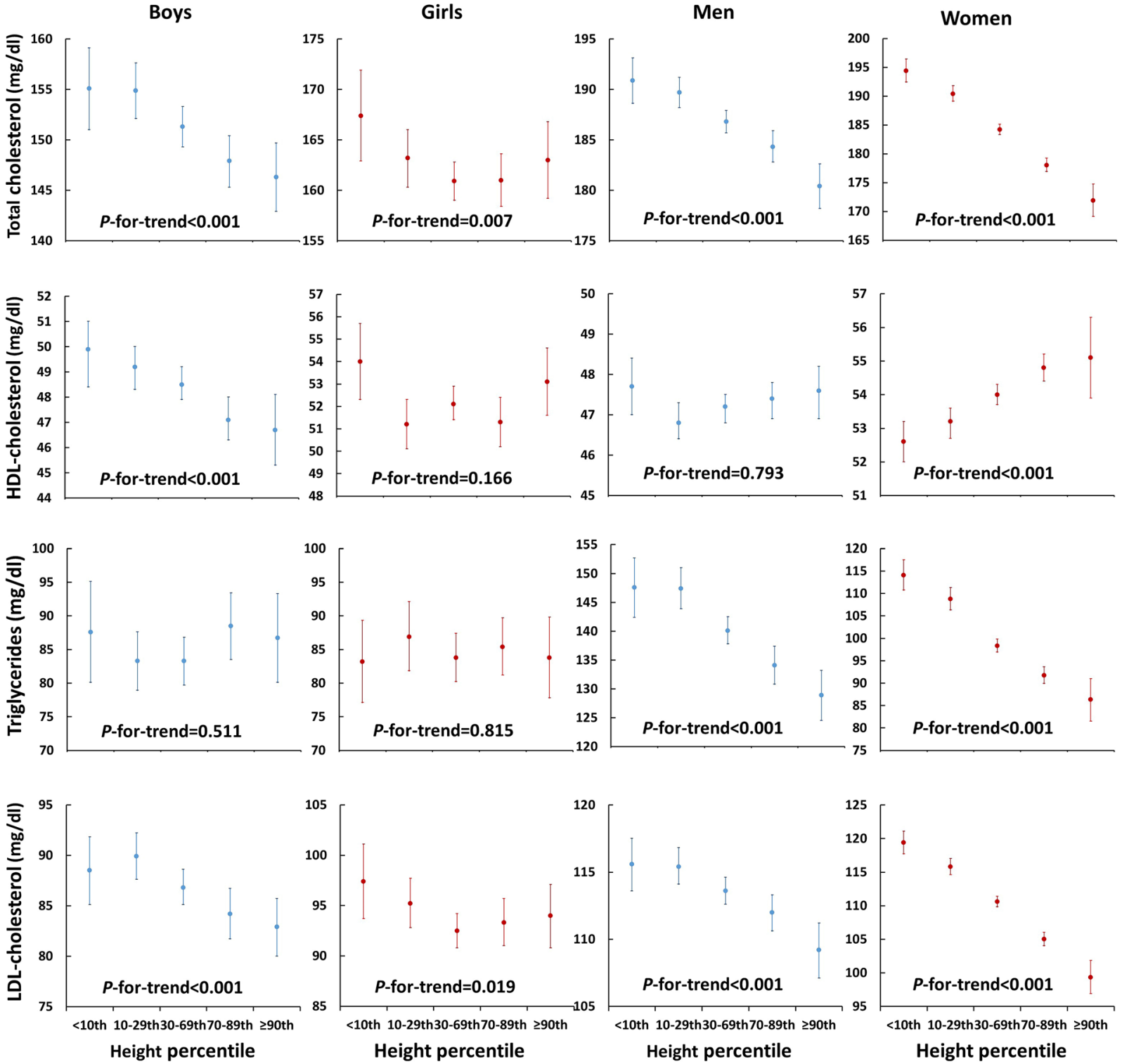

Figure 1. Relationship between the lipid profile and height percentile. The data were presented as mean and 95\% confidence intervals (error bars).

for overall dyslipidemia in non-obese male patients was significantly decreased in taller subjects ${ }^{17}$. The present findings suggest that height in adulthood is favorably associated with not only LDL-C and HDL-C levels, but also TG levels. This finding is consistent with that of a recent genome-wide association study, which reported that increased height-raising allele was associated with decreased LDL-C and TG levels ${ }^{18}$.

An interesting fact in this study population was that taller adults tend to have higher alcohol consumption and physical activity compared with shorter adults. Higher alcohol consumption had been related to higher HDL-cholesterol in previous studies, but its beneficial effect on CVD risk is known to be alleviated by TG-elevating effect of alcohol ${ }^{19}$. Unlike alcohol consumption with conflicting effects on CVD risk, beneficial effects of physical activity on the lipid profiles, including lowering LDL-cholesterol and triglycerides, and increasing HDL-cholesterol have been consistently reported by previous studies ${ }^{20}$. To eliminate the possible favorable impact of these lifestyle factors on lipid profiles, we included these confounding factors for final adjustment. Another thing that we have to note is an inverted J-shaped association between OR for hyper-HDL-cholesterolemia and height in women. We could not find any difference in age and confounding factors between the shortest women (height $<10^{\text {th }}$ percentile) and the next shortest women (height $10 \sim 29^{\text {th }}$ percentile). There has been no report of an inverted J-shaped association between height and HDL-cholesterol similar to our result. In overall, a favorable trend for hypo-HDL-cholesterolemia according to the height increase was found in women. Therefore, further research is needed to determine whether the risk of hypo-HDL-cholesterolemia is rather alleviated in severe short stature compared with mild short stature in women.

There were gender-related differences in the relationships between height and lipid profiles. In both adults and adolescents, lipid profiles in males tended to be more clearly affected by short stature. Boys with short 

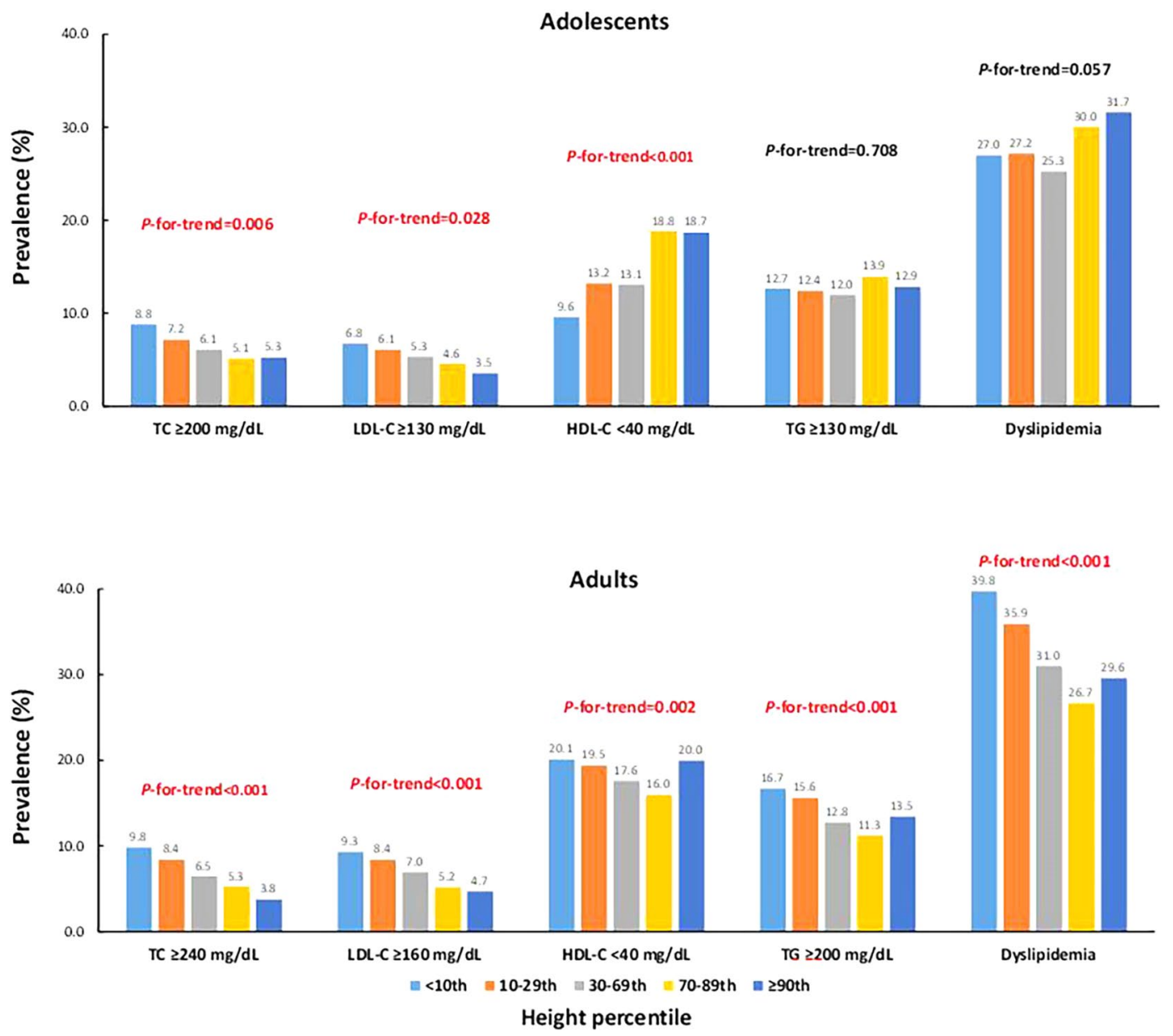

Figure 2. Prevalence of adverse lipid profile according to the height percentile.

stature showed a remarkably increased risk of both hyper-LDL-cholesterolemia $(\mathrm{OR}=4.35)$ and hypertriglyceridemia $(\mathrm{OR}=2.38)$, while girls with short stature showed an increased risk of hyper-LDL-cholesterolemia only $(\mathrm{OR}=3.12)$. Likewise, the unfavorable effects of short stature in hypertriglyceridemia and hypo-HDL-cholesterolemia were more evident in men than in women. This gender difference can be explained by the beneficial effects of estrogen on lipid metabolism. Estrogen increases the accumulation of subcutaneous fat and restrains the increase of visceral fat, consequently allows a metabolically favorable distribution of adipose tissue $^{21}$. Also, estrogen promotes reverse cholesterol transport process, such as hepatic secretion of cholesterol into bile, and reduces hepatic TG content through hepatic estrogen receptor $\alpha^{21}$.

The mechanisms supporting the link between height and dyslipidemia are not currently clear. Two hormones that play a decisive role in bone growth are growth hormone $(\mathrm{GH})$ and thyroid hormone, both of which contribute to the improvement of lipid profiles. The lipolytic action of GH has been well described, particularly on visceral fat, and the administration of recombinant human GH in children and adults with GH deficiency or obesity has been reported to improve lipid metabolism by reducing TC and LDL-C levels ${ }^{22,23}$. In addition, it is well known that thyroid hormone plays an important role in hepatic synthesis and metabolism of fatty acids and cholesterol, and hypothyroidism leads to hypercholesterolemia and hypertriglyceridemia ${ }^{24}$. Therefore, it can be inferred that adolescents with adequate $\mathrm{GH}$ and thyroid hormone secretion are likely to have optimal growth and lipid profiles. In addition, since cholesterol is an essential component of cell membranes and steroid hormones, serum cholesterol may be lowered in individuals with a high growth velocity due to increased cholesterol consumption ${ }^{12}$. The skeletal system is now recognized as an important endocrine organ, which is involved in lipid metabolism. Several studies have shown that blood fatty acids are taken up by the skeletal system and are used as an energy source by the osteoblasts, thereby clearing circulating lipoproteins and non-esterified fatty acids ${ }^{25}$. In addition, osteocalcin, an osteoblast-derived hormone, increases the expression of the adiponectin gene in adipocytes ${ }^{26}$. Adiponectin causes an increase in serum HDL via inducing an increase in the hepatic production of apolipoprotein A-1 and the ATP-binding cassette transporter $\mathrm{A}^{27}$. Additionally, adiponectin lowers serum TG by enhancing VLDL catabolism in skeletal muscle adipose tissue ${ }^{27}$. Therefore, high osteocalcin levels in adolescents with high growth rates ${ }^{28}$ may result in favorable lipid profiles ${ }^{29}$. Finally, as noted above, a recent genome-wide association study reported a correlation between genetically determined short height and increased risk of coronary artery disease, which is partly explained by an association between height-related single nucleotide polymorphisms and lipid profiles, especially those of LDL-C and $\mathrm{TG}^{18}$. 


\begin{tabular}{|c|c|c|c|c|c|c|}
\hline & \multicolumn{5}{|l|}{ Height percentile } & \multirow{3}{*}{$\begin{array}{l}\text { P-for- } \\
\text { trend }\end{array}$} \\
\hline & \multirow{2}{*}{\begin{tabular}{|l|}
$<10$ th \\
OR $(95 \% \mathrm{CI})$ \\
\end{tabular}} & \multirow{2}{*}{\begin{tabular}{|l|}
$10-29$ th \\
OR $(95 \% \mathrm{CI})$ \\
\end{tabular}} & \multirow{2}{*}{\begin{tabular}{l|} 
30-69th \\
OR (95\% CI)
\end{tabular}} & \multirow{2}{*}{\begin{tabular}{|l|}
$70-89$ th \\
OR $(95 \%$ CI
\end{tabular}} & \multirow{2}{*}{\begin{tabular}{|l|}
$\geq 90$ th \\
OR $(95 \% \mathrm{CI})$ \\
\end{tabular}} & \\
\hline & & & & & & \\
\hline \multicolumn{7}{|c|}{ 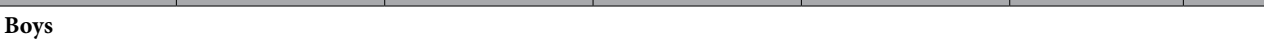 } \\
\hline \multicolumn{7}{|c|}{$\mathrm{TC} \geq 200 \mathrm{mg} / \mathrm{dL}$} \\
\hline Model 1 & $3.06(1.01-9.24)$ & $3.86(1.42-10.5)$ & $3.01(1.13-8.01)$ & $2.05(0.71-5.93)$ & ref & 0.006 \\
\hline Model 2 & $7.01(2.26-21.7)$ & $6.60(2.39-18.3)$ & $3.72(1.38-10.1)$ & $2.18(0.75-6.29)$ & ref & $<0.001$ \\
\hline \multicolumn{7}{|c|}{ HDL-C $<40 \mathrm{mg} / \mathrm{dL}$} \\
\hline Model 1 & $0.42(0.24-0.74)$ & $0.52(0.34-0.78)$ & $0.58(0.38-0.87)$ & $0.90(0.60-1.35)$ & ref & $<0.001$ \\
\hline Model 2 & $0.69(0.37-1.27)$ & $0.68(0.43-1.06)$ & $0.72(0.47-1.11)$ & $0.99(0.63-1.54)$ & ref & 0.271 \\
\hline \multicolumn{7}{|c|}{$\mathrm{TG} \geq 130 \mathrm{mg} / \mathrm{dL}$} \\
\hline Model 1 & $1.10(0.11-0.25)$ & $0.87(0.62-1.96)$ & $0.91(0.59-1.40)$ & $1.09(0.67-1.78)$ & ref & 0.997 \\
\hline Model 2 & $2.38(1.21-4.66)$ & $1.55(0.87-2.12)$ & $1.31(0.81-2.12)$ & $1.20(0.68-2.08)$ & ref & 0.048 \\
\hline \multicolumn{7}{|c|}{$\mathrm{LDL}-\mathrm{C} \geq 130 \mathrm{mg} / \mathrm{dL}$} \\
\hline Model 1 & $1.56(0.57-4.28)$ & $2.94(1.25-6.89)$ & $2.17(0.94-5.01)$ & $1.28(0.49-3.34)$ & ref & 0.050 \\
\hline Model 2 & $4.35(1.48-12.8)$ & $5.48(2.23-13.6)$ & $3.05(1.28-7.23)$ & $1.34(0.51-3.51)$ & ref & $<0.001$ \\
\hline \multicolumn{7}{|c|}{ Dyslipidemia } \\
\hline Model 1 & $0.73(0.46-1.14)$ & $0.72(0.49-1.04)$ & $0.66(0.46-0.94)$ & $0.90(0.62-1.30)$ & ref & 0.074 \\
\hline Model 2 & $1.36(0.81-2.27)$ & $1.11(0.74-1.66)$ & $0.86(0.59-1.26)$ & $1.00(0.67-1.50)$ & ref & 0.092 \\
\hline \multicolumn{7}{|l|}{ Girls } \\
\hline \multicolumn{7}{|c|}{$\mathrm{TC} \geq 200 \mathrm{mg} / \mathrm{dL}$} \\
\hline Model 1 & $1.48(0.75-2.92)$ & $0.88(0.47-1.65)$ & $0.78(0.44-1.39)$ & $0.75(0.40-1.40)$ & ref & 0.237 \\
\hline Model 2 & $1.92(0.96-3.82)$ & $1.07(0.56-2.04)$ & $0.83(0.46-1.49)$ & $0.80(0.42-1.51)$ & ref & 0.063 \\
\hline \multicolumn{7}{|c|}{$\mathrm{HDL}-\mathrm{C}<40 \mathrm{mg} / \mathrm{dL}$} \\
\hline Model 1 & $0.56(0.25-1.24)$ & $1.05(0.60-1.83)$ & $0.86(0.53-1.39)$ & $1.27(0.74-2.17)$ & ref & 0.061 \\
\hline Model 2 & $0.81(0.32-2.03)$ & $1.30(0.74-2.30)$ & $1.05(0.63-1.76)$ & $1.35(0.78-2.37)$ & ref & 0.396 \\
\hline \multicolumn{7}{|c|}{$\mathrm{TG} \geq 130 \mathrm{mg} / \mathrm{dL}$} \\
\hline Model 1 & $1.23(0.58-2.58)$ & $1.40(0.74-2.66)$ & $1.09(0.63-1.88)$ & $1.13(0.61-2.08)$ & ref & 0.571 \\
\hline Model 2 & $1.19(0.56-2.53)$ & $1.42(0.75-2.70)$ & $1.10(0.64-1.89)$ & $1.15(0.62-2.13)$ & ref & 0.749 \\
\hline \multicolumn{7}{|c|}{$\mathrm{LDL}-\mathrm{C} \geq 130 \mathrm{mg} / \mathrm{dL}$} \\
\hline Model 1 & $0.45(0.20-1.01)$ & $0.82(0.39-1.72)$ & $0.82(0.41-1.63)$ & $0.75(0.37-1.53)$ & ref & 0.225 \\
\hline Model 2 & $3.12(1.38-7.09)$ & $1.71(0.81-3.64)$ & $1.37(0.68-2.75)$ & $1.46(0.70-3.04)$ & ref & 0.026 \\
\hline \multicolumn{7}{|c|}{ Dyslipidemia } \\
\hline Model 1 & $0.91(0.57-1.45)$ & $0.94(0.63-1.41)$ & $0.83(0.58-1.20)$ & $0.96(0.64-1.43)$ & ref & 0.400 \\
\hline Model 2 & $1.33(0.80-2.21)$ & $1.20(0.78-1.84)$ & $0.96(0.65-1.43)$ & $1.03(0.67-1.57)$ & ref & 0.253 \\
\hline
\end{tabular}

Table 3. Adjusted odds ratios (95\% confidence interval) for dyslipidemia in adolescents according to the height percentile. Model 1: Unadjusted. Model 2: Adjusted for age, waist circumference, systolic/diastolic blood pressure, fasting glucose levels, household income, physical activity, and alcohol consumption. CI, confidence interval; HDL-C, high density lipoprotein-cholesterol; LDL-C, low density lipoprotein-cholesterol; OR, odd ratio; TC, total cholesterol; TG, triglycerides.

Our study does have some limitations. As this was a cross-sectional study, causality could not be inferred between short stature and dyslipidemia. In addition, we did not examine some confounding factors, such as pubertal stage, dietary intakes and family history of dyslipidemia. Nonetheless, to the best of our knowledge, this is the first study that reports the association of the profiles of all lipids, including TG, with height in adults as well as in adolescents, using nationally representative data. We tried to minimize the age-associated bias by using age or age-group specific height percentile. We also included various covariates including age, waist circumference, blood pressures, fasting glucose, and lifestyle factors, that are known to be potentially related to lipid profiles in the statistical analysis.

In conclusion, this study presents the evidence of short stature as associated with adverse lipid profiles in both adolescents and adults, and also suggests possible mechanisms to explain this association. Our results may help partly explain the association between short height and increased risk of CVD.

\section{Methods}

Study population. We analyzed data from the Korean National Health and Nutrition Examination Survey (KNHANES), conducted by the Korean Centers for Disease Control and Prevention between 2007 and 2015. This nationwide cross-sectional survey includes demographic and anthropometric information, lipid profiles and information on health-related behaviors, including alcohol intake, physical activity and household income. We limited the analyses to individuals aged 12-59 years. Among the potentially eligible 44,448 individuals, we excluded participants for whom incomplete data were available for lipid profiles and anthropometric 


\begin{tabular}{|c|c|c|c|c|c|c|}
\hline & \multicolumn{5}{|l|}{ Height percentile } & \multirow[b]{3}{*}{ P-for-trend } \\
\hline & $<10$ th & 10-29th & 30-69th & 70-89th & $\geq 90$ th & \\
\hline & OR $(95 \% \mathrm{CI})$ & OR $(95 \% \mathrm{CI})$ & OR $(95 \% \mathrm{CI})$ & OR $(95 \% \mathrm{CI})$ & OR $(95 \% \mathrm{CI})$ & \\
\hline \multicolumn{7}{|l|}{ Men } \\
\hline \multicolumn{7}{|c|}{$\mathrm{TC} \geq 240 \mathrm{mg} / \mathrm{dL}$} \\
\hline Model 1 & $1.91(1.32-2.74)$ & $2.01(1.44-2.81)$ & $1.54(1.13-2.12)$ & $1.53(1.11-2.12)$ & ref & $<0.001$ \\
\hline Model 2 & $1.84(1.23-2.74)$ & $1.87(1.31-2.69)$ & $1.51(1.09-2.11)$ & $1.51(1.09-2.11)$ & ref & 0.004 \\
\hline \multicolumn{7}{|c|}{$\mathrm{HDL}-\mathrm{C}<40 \mathrm{mg} / \mathrm{dL}$} \\
\hline Model 1 & $1.27(1.04-1.56)$ & $1.17(0.98-1.40)$ & $1.14(0.97-1.34)$ & $1.04(0.87-1.23)$ & ref & 0.045 \\
\hline Model 2 & $1.50(1.19-1.89)$ & $1.29(1.05-1.58)$ & $1.26(1.04-1.51)$ & $1.12(0.93-1.36)$ & ref & 0.003 \\
\hline \multicolumn{7}{|c|}{$\mathrm{TG} \geq 200 \mathrm{mg} / \mathrm{dL}$} \\
\hline Model 1 & $1.58(1.27-1.96)$ & $1.50(1.24-1.82)$ & $1.27(1.07-1.52)$ & $1.12(0.92-1.36)$ & ref & $<0.001$ \\
\hline Model 2 & $1.85(1.44-2.38)$ & $1.64(1.32-2.05)$ & $1.37(1.12-1.68)$ & $1.18(0.94-1.47)$ & ref & $<0.001$ \\
\hline \multicolumn{7}{|c|}{ LDL-C $\geq 160 \mathrm{mg} / \mathrm{dL}$} \\
\hline Model 1 & $1.52(1.05-2.21)$ & $1.61(1.17-2.21)$ & $1.47(1.08-1.99)$ & $1.25(0.90-1.73)$ & ref & 0.001 \\
\hline Model 2 & $1.56(1.05-2.32)$ & $1.60(1.14-2.27)$ & $1.51(1.10-2.07)$ & $1.28(0.92-1.78)$ & ref & 0.026 \\
\hline \multicolumn{7}{|c|}{ Dyslipidemia } \\
\hline Model 1 & $1.69(1.41-2.02)$ & $1.51(1.29-1.76)$ & $1.33(1.15-1.54)$ & $1.16(0.99-1.36)$ & ref & $<0.001$ \\
\hline Model 2 & $1.93(1.57-2.39)$ & $1.62(1.35-1.93)$ & $1.44(1.22-1.70)$ & $1.26(1.05-1.47)$ & ref & $<0.001$ \\
\hline \multicolumn{7}{|l|}{ Women } \\
\hline \multicolumn{7}{|c|}{ LDL-C $\geq 160 \mathrm{mg} / \mathrm{dL}$} \\
\hline Model 1 & $6.76(3.75-12.2)$ & $4.75(2.67-8.45)$ & $3.50(1.96-6.25)$ & $2.22(1.22-4.05)$ & ref & $<0.001$ \\
\hline Model 2 & $2.61(1.41-4.81)$ & $2.12(1.17-3.84)$ & $2.01(1.11-3.63)$ & $1.64(0.89-3.02)$ & ref & $<0.001$ \\
\hline \multicolumn{7}{|c|}{$\mathrm{HDL}-\mathrm{C}<40 \mathrm{mg} / \mathrm{dL}$} \\
\hline Model 1 & $1.48(0.99-2.21)$ & $1.56(1.05-2.33)$ & $1.22(0.83-1.79)$ & $0.99(0.66-1.46)$ & ref & $<0.001$ \\
\hline Model 2 & $1.33(0.86-2.04)$ & $1.54(1.02-2.33)$ & $1.28(0.86-1.91)$ & $1.12(0.74-1.68)$ & ref & 0.003 \\
\hline \multicolumn{7}{|c|}{$\mathrm{TG} \geq 200 \mathrm{mg} / \mathrm{dL}$} \\
\hline Model 1 & $2.24(1.40-3.60)$ & $1.99(1.26-3.13)$ & $1.39(0.89-2.19)$ & $1.11(0.69-1.77)$ & ref & $<0.001$ \\
\hline Model 2 & $1.34(0.78-2.31)$ & $1.35(0.81-2.29)$ & $1.11(0.67-1.85)$ & $1.06(0.63-1.79)$ & ref & 0.087 \\
\hline \multicolumn{7}{|c|}{ LDL-C $\geq 160 \mathrm{mg} / \mathrm{dL}$} \\
\hline Model 1 & $4.70(2.64-8.33)$ & $3.62(2.06-6.35)$ & $2.64(1.50-4.64)$ & $1.57(0.87-2.83)$ & ref & $<0.001$ \\
\hline Model 2 & $1.84(1.03-3.30)$ & $1.71(0.97-3.01)$ & $1.52(0.87-2.67)$ & $1.19(0.66-2.13)$ & ref & 0.002 \\
\hline \multicolumn{7}{|c|}{ Dyslipidemia } \\
\hline Model 1 & $3.09(2.27-4.20)$ & $2.49(1.85-3.36)$ & $1.80(1.34-2.40)$ & $1.24(0.92-1.68)$ & ref & $<0.001$ \\
\hline Model 2 & $1.88(1.35-2.61)$ & $1.79(1.31-2.45)$ & $1.52(1.12-2.06)$ & $1.27(0.93-1.73)$ & ref & $<0.001$ \\
\hline
\end{tabular}

Table 4. Adjusted odds ratios (95\% confidence interval) for dyslipidemia in adults according to the height percentile. Model 1: Unadjusted. Model 2: Adjusted for age, waist circumference, systolic/diastolic blood pressure, fasting glucose levels, household income, physical activity, alcohol consumption, and menopause status (for women). CI, confidence interval; HDL-C, high density lipoprotein-cholesterol; LDL-C, low density lipoprotein-cholesterol; OR, odd ratio; TC, total cholesterol; TG, triglycerides.

measurements $(\mathrm{n}=5463)$. Other exclusion criteria included serum triglycerides $\geq 400 \mathrm{mg} / \mathrm{dL}(\mathrm{n}=784)$; medical history of liver cirrhosis, nephrotic syndrome, or endocrine disorders; and use of medications affecting blood lipid concentrations $(n=312)$. Eventually, 37,889 individuals aged $12-59$ years who completed blood tests for lipid profiles after an overnight fast were enrolled in this study, comprising 5,207 adolescents (2,776 boys and 2,431 girls, aged 12-18 years) and 32,682 adults (13,644 men and 19,038 women, aged 19-59 years). The KNHANES protocol was approved by an Institutional Review Board of the Korean Centers for Disease Control and Prevention (IRB No. 2007-02CON-04-P, 2008-04EXP-01-C, 2009-01CON-03-2C, 2010-02CON-21-C, 2011-02CON-06-C, 2012-01EXP-01-2C, 2013-07CON-03-4C, and 2013-12EXP-03-5C), and conducted according to the Declaration of Helsinki. All participants or their parents/guardians provided written informed consent form. This study was approved by the institutional review board of Inje University, Sanggye Paik Hospital (IRB No. SGPAIK 2019-02-005), which waived the requirement for informed consent due to the anonymity of the data obtained from the KNHANES dataset.

Data collection and study variables. Participant height and body weight were measured to the nearest $0.1 \mathrm{~cm}$ using a stadiometer and $0.1 \mathrm{~kg}$ using a digital weight scale, respectively. BMI was calculated as the weight $(\mathrm{kg})$ divided by the square of the height $(\mathrm{m})$. Waist circumference was measured following a full expiration at the narrowest point between the bottom of the $10^{\text {th }} \mathrm{rib}$ and the superior border of the iliac crest. Systolic and diastolic blood pressure were measured using a standard mercury sphygmomanometer on the right arm on three occasions while the participants in a sitting position after they rested for more than 10 minutes. The final blood pressure values used for analysis were the average values of three measurements. 
Blood collections were performed via venipunctures from the antecubital fossa after a fasting period of at least $8 \mathrm{~h}$. In 2007, serum concentrations of TC, HDL-C, TG and fasting glucose were measured enzymatically using an ADIVIA 1650 (Siemens, New York, USA). Serum LDL-C levels were calculated using Friedewald's formula ${ }^{30}$. In 2008-2015, serum fasting glucose and lipid profiles, including LDL-C, were determined enzymatically using a Hitachi Automatic Analyzer 7600 (Hitachi, Tokyo, Japan). Participants were categorized as five groups according to the height percentile $\left(<10^{\text {th }}, 10-29^{\text {th }}, 30-69^{\text {th }}, 70-89^{\text {th }}, \geq 90^{\text {th }}\right.$ percentile). Sex and age-specific height percentile was applied for adolescents, and sex and age group-specific (under the $30 \mathrm{~s}, 30 \mathrm{~s}, 40 \mathrm{~s}$, and $50 \mathrm{~s}$ ) height percentile was applied for adults. The sex and age-specific height percentile values were presented Supplementary Table S3. Household income was categorized into quartiles based on the equalization of income, calculated as monthly family income divided by the square root of the number of family members. Alcohol consumption was marked as "occasionally" for a subject consuming at least one drink per month in the previous year and "excessively" when the subject consumed seven drinks or more (for males) or five drinks or more (for females) on a single occasion more than 2 times a week. Alcohol consumption less than once per month in the past year was classified as "none". Physically active persons were defined as subjects performing regular vigorous activity at least 20 minutes per session for 3 or more days per week.

Definition of dyslipidemia. Dyslipidemia was defined as the presence of at least one of the following: hypercholesterolemia, hypertriglyceridemia, hyper-LDL-cholesterolemia, and hypo-HDL-cholesterolemia. In children and adolescents, hypercholesterolemia $(\geq 200 \mathrm{mg} / \mathrm{dL})$, hypertriglyceridemia $(\geq 130 \mathrm{mg} / \mathrm{dL})$; hyper-LDL-cholesterolemia $(\geq 130 \mathrm{mg} / \mathrm{dL})$, and hypo-HDL-cholesterolemia $(<40 \mathrm{mg} / \mathrm{dL})$ were defined per the National Heart, Lung, and Blood Institute's (NHLBI) Expert Panel Guidelines ${ }^{31}$. In adults, hypercholesterolemia $(\geq 240 \mathrm{mg} / \mathrm{dL})$, hypertriglyceridemia $(\geq 200 \mathrm{mg} / \mathrm{dL})$, hyper-LDL-cholesterolemia $(\geq 160 \mathrm{mg} / \mathrm{dL})$, and hypo-HDL-cholesterolemia $(<40 \mathrm{mg} / \mathrm{dL})$ were determined according to the Korean Society of Lipid and Atherosclerosis guidelines for adults ${ }^{32}$.

Statistical analysis. Statistical analyses were performed using SPSS version 21.0 (SPSS, Inc., Chicago, IL, USA). The complex samples descriptive procedure was used to evaluate the mean and standard error of scale variables. The complex samples crosstabs procedure was used for categorical or ordinal variables. The complex samples general linear model was used to compare serum concentrations of lipid profiles according to the height percentile and to calculate $P$ values for trend. Multiple logistic regression analyses were used to calculate the ORs for dyslipidemia according to the height percentile after adjusting for covariates including age, waist circumference, systolic/diastolic blood pressure, fasting glucose, household income (quartile 1,2,3,4), physical activity (yes, no), alcohol consumption (no, occasionally, excessively), and menopausal status (yes, no). TG levels were log-transformed owing to their skewed distribution. For all analyses, $\mathrm{P}$-values were two-tailed and $\mathrm{P}<0.05$ was considered statistically significant.

\section{References}

1. Paajanen, T. A., Oksala, N. K., Kuukasjarvi, P. \& Karhunen, P. J. Short stature is associated with coronary heart disease: a systematic review of the literature and a meta-analysis. Eur Heart J 31, 1802-1809, https://doi.org/10.1093/eurheartj/ehq155 (2010).

2. Emerging Risk Factors, C. Adult height and the risk of cause-specific death and vascular morbidity in 1 million people: individual participant meta-analysis. Int J Epidemiol 41, 1419-1433, https://doi.org/10.1093/ije/dys086 (2012).

3. Song, Y. M., Smith, G. D. \& Sung, J. Adult height and cause-specific mortality: a large prospective study of South Korean men. Am J Epidemiol 158, 479-485 (2003).

4. Song, Y. M. \& Sung, J. Adult height and the risk of mortality in South Korean women. Am J Epidemiol 168, 497-505, https://doi. org/10.1093/aje/kwn187 (2008).

5. Henriksson, K. M., Lindblad, U., Agren, B., Nilsson-Ehle, P. \& Rastam, L. Associations between body height, body composition and cholesterol levels in middle-aged men. the coronary risk factor study in southern Sweden (CRISS). Eur J Epidemiol 17, 521-526 (2001).

6. Skidmore, P. M., Hardy, R. J., Kuh, D. J., Langenberg, C. \& Wadsworth, M. E. Life course body size and lipid levels at 53 years in a British birth cohort. J Epidemiol Community Health 61, 215-220, https://doi.org/10.1136/jech.2006.047571 (2007).

7. Schooling, C. M. et al. Height, its components, and cardiovascular risk among older Chinese: a cross-sectional analysis of the Guangzhou Biobank Cohort Study. Am J Public Health 97, 1834-1841, https://doi.org/10.2105/AJPH.2006.088096 (2007).

8. Berenson, G. S. et al. Association between multiple cardiovascular risk factors and atherosclerosis in children and young adults. The Bogalusa Heart Study. N Engl J Med 338, 1650-1656, https://doi.org/10.1056/NEJM199806043382302 (1998).

9. Kim, S. H., Ahn, B. C., Joung, H. \& Park, M. J. Lipid Profiles and Prevalence of Dyslipidemia in Korean Adolescents. Endocrinol Metab 27, 208-216 (2012).

10. Orchard, T. J., Rodgers, M., Hedley, A. J. \& Mitchell, J. R. Changes in blood lipids and blood pressure during adolescence. Br Med J 280, 1563-1567 (1980).

11. Chu, N. F., Rimm, E. B., Wang, D. J., Liou, H. S. \& Shieh, S. M. Relationship between anthropometric variables and lipid levels among school children: The Taipei Children Heart Study. Int J Obes Relat Metab Disord 22, 66-72 (1998).

12. Chiang, Y. K., Srinivasan, S. R., Webber, L. S. \& Berenson, G. S. Relationship between change in height and changes in serum lipid and lipoprotein levels in adolescent males: the Bogalusa Heart Study. J Clin Epidemiol 42, 409-415 (1989).

13. Kouda, K., Nakamura, H., Fan, W. \& Takeuchi, H. Negative relationships between growth in height and levels of cholesterol in puberty: a 3-year follow-up study. Int J Epidemiol 32, 1105-1110 (2003).

14. Fujita, Y., Kouda, K., Nakamura, H. \& Iki, M. Inverse association between height increase and LDL cholesterol during puberty: A 3-year follow-up study of the Fukuroi City. Am J Hum Biol 28, 330-334, https://doi.org/10.1002/ajhb.22784 (2016).

15. Pyles, L. A. et al. LDL cholesterol level in fifth-grade schoolchildren associates with stature. J Lipid Res 58, 2197-2201, https://doi. org/10.1194/jlr.P078816 (2017)

16. Walter, M. Interrelationships among HDL metabolism, aging, and atherosclerosis. Arterioscler Thromb Vasc Biol 29, 1244-1250, https://doi.org/10.1161/ATVBAHA.108.181438 (2009).

17. Shimizu, Y. et al. Height correlates with dyslipidemia in non-overweight middle-aged Japanese men. J Physiol Anthropol 35, 29, https://doi.org/10.1186/s40101-016-0119-1 (2016).

18. Nelson, C. P. et al. Genetically determined height and coronary artery disease. N Engl J Med 372, 1608-1618, https://doi.org/10.1056/ NEJMoa1404881 (2015). 
19. Rimm, E. B., Williams, P., Fosher, K., Criqui, M. \& Stampfer, M. J. Moderate alcohol intake and lower risk of coronary heart disease: meta-analysis of effects on lipids and haemostatic factors. BMJ 319, 1523-1528, https://doi.org/10.1136/bmj.319.7224.1523 (1999).

20. Kim, S. H., Song, Y. H., Park, S. \& Park, M. J. Impact of lifestyle factors on trends in lipid profiles among Korean adolescents: the Korea National Health and Nutrition Examination Surveys study, 1998 and 2010. Korean J Pediatr 59, 65-73, https://doi. org/10.3345/kjp.2016.59.2.65 (2016).

21. Palmisano, B. T., Zhu, L., Eckel, R. H. \& Stafford, J. M. Sex differences in lipid and lipoprotein metabolism. Mol Metab 15, 45-55, https://doi.org/10.1016/j.molmet.2018.05.008 (2018).

22. Liang, S., Xue, J. \& Li, G. Effects of recombinant human growth hormone administration on cardiovascular risk factors in obese children with relative growth hormone deficiency. Lipids Health Dis 17, 66, https://doi.org/10.1186/s12944-018-0721-9 (2018).

23. De Marco, S. et al. Circulating asymmetric dimethylarginine and lipid profile in pre-pubertal children with growth hormone deficiency: effect of 12-month growth hormone replacement therapy. Growth Horm IGF Res 24, 216-220, https://doi.org/10.1016/j. ghir.2014.08.001 (2014).

24. Sinha, R. A., Singh, B. K. \& Yen, P. M. Direct effects of thyroid hormones on hepatic lipid metabolism. Nat Rev Endocrinol 14, 259-269, https://doi.org/10.1038/nrendo.2018.10 (2018).

25. Kushwaha, P., Wolfgang, M. J. \& Riddle, R. C. Fatty acid metabolism by the osteoblast. Bone 115, 8-14, https://doi.org/10.1016/j. bone.2017.08.024 (2018).

26. Lee, N. K. et al. Endocrine regulation of energy metabolism by the skeleton. Cell 130, 456-469, https://doi.org/10.1016/j. cell.2007.05.047 (2007).

27. Yanai, H. \& Yoshida, H. Beneficial Effects of Adiponectin on Glucose and Lipid Metabolism and Atherosclerotic Progression: Mechanisms and Perspectives. Int J Mol Sci 20, https://doi.org/10.3390/ijms20051190 (2019).

28. Kanbur, N. O., Derman, O., Sen, T. A. \& Kinik, E. Osteocalcin. A biochemical marker of bone turnover during puberty. Int J Adolesc Med Health 14, 235-244 (2002).

29. Chen, Y., Zhao, Q., Du, G. \& Xu, Y. Association between serum osteocalcin and glucose/lipid metabolism in Chinese Han and Uygur populations with type 2 diabetes mellitus in Xinjiang: two cross-sectional studies. Lipids Health Dis 16, 139, https://doi.org/10.1186/ s12944-017-0512-8 (2017).

30. Friedewald, W. T., Levy, R. I. \& Fredrickson, D. S. Estimation of the concentration of low-density lipoprotein cholesterol in plasma, without use of the preparative ultracentrifuge. Clin Chem 18, 499-502 (1972).

31. Expert Panel on Integrated Guidelines for Cardiovascular, H., Risk Reduction in, C., Adolescents, National Heart, L. \& Blood, I. Expert panel on integrated guidelines for cardiovascular health and risk reduction in children and adolescents: summary report. Pediatrics 128(Suppl 5), S213-256, https://doi.org/10.1542/peds.2009-2107C (2011).

32. Expert Panel on Detection, E. \& Treatment of High Blood Cholesterol in, A. Executive Summary of The Third Report of The National Cholesterol Education Program (NCEP) Expert Panel on Detection, Evaluation, And Treatment of High Blood Cholesterol In Adults (Adult Treatment Panel III). JAMA 285, 2486-2497 (2001).

\section{Acknowledgements}

We thank the Korea Centers for Disease Control and Prevention for providing the data.

\section{Author Contributions}

M.J. Park and S.-H. Kim designed the study concept. S.-H. Kim constructed the database set and assisted statistical analysis. N.-K. Oh and Y.-M. Song wrote the manuscript. All authors discussed data and reviewed manuscript.

\section{Additional Information}

Supplementary information accompanies this paper at https://doi.org/10.1038/s41598-019-50524-2.

Competing Interests: The authors declare no competing interests.

Publisher's note Springer Nature remains neutral with regard to jurisdictional claims in published maps and institutional affiliations.

(c) (i) Open Access This article is licensed under a Creative Commons Attribution 4.0 International License, which permits use, sharing, adaptation, distribution and reproduction in any medium or format, as long as you give appropriate credit to the original author(s) and the source, provide a link to the Creative Commons license, and indicate if changes were made. The images or other third party material in this article are included in the article's Creative Commons license, unless indicated otherwise in a credit line to the material. If material is not included in the article's Creative Commons license and your intended use is not permitted by statutory regulation or exceeds the permitted use, you will need to obtain permission directly from the copyright holder. To view a copy of this license, visit http://creativecommons.org/licenses/by/4.0/.

(C) The Author(s) 2019 